\section{The White House Conference and the National Research and Education Network: A timely partnership}

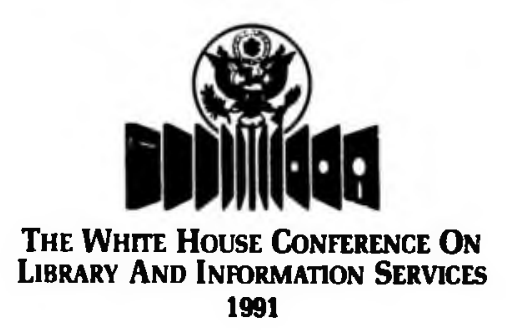

\author{
By David Bishop \\ University Librarian, University of Illinois, and \\ Member, ACRL Task Force on White House Conference
}

The White House Conference on Libraries and Information Service (WHCLIS) provides an ideal opportunity for librarians to continue their leadership role in telecommunications and in establishing the National Research and Education Network (NREN). The High Performance Computing Act of 1991, which includes funding for the NREN, has been reintroduced by Sen. Albert Gore and $18 \mathrm{co-}$ sponsors. A similar bill has been introduced in the House. It is crucial that WHCLIS adopt a forceful position in support of the concept of a high-speed national network. The theme of the White House Conference is literacy, productivity, and democracy. The development of advanced telecommunications capabilities will clearly be necessary if the colleges and universities of this country are to achieve those goals.

The growing emphasis on telecommunications in libraries during the last few years has been remarkable. Most libraries are now connected to one of the major bibliographic utilities and a number of libraries also have connections to vendors, enabling them to place book orders and claim missing journal issues electronically. Libraries are increasingly using general networks to obtain services from bibliographic database providers such as BRS and DIALOG. The use of FAX has increased dramatically, both for general use and to provide rapid delivery of library materials. The use of electronic mail continues to grow, both for general communications among libraries and for the transmission of specific information for users. And finally, libraries, using existing academic networks, are beginning to provide access to the online catalogs of other libraries and to bibliographic and full-text databases.

Advances in general telecommunication capabilities on college and university campuses have been similar to those in libraries. Sophisticated campus networks are emerging that provide faculty and students with a wide range of campus services as well as providing gateways that allow access to services located around the world. For the library, these campus networks allow library services to be provided throughout the campus and provide the capability for libraries to become switching centers that will provide information from a variety of sources.

While the progress made in telecommunications in higher education is dramatic and exciting, there is a problem. The networks that connect our colleges and universities are clearly inadequate to meet today's needs and will become more inadequate in the future. The growth in the number of users, the increase in the amount of use by each individual, and the development of more resourceintensive applications, such as imaging, have all caused these networks to be strained well beyond their capacities. We run the risk of developing computing capabilities and a set of user expectations, only to have inadequate networks result in a degradation of service that will cause user frustration and disillusionment.

The proposed National Research and Education Network or NREN is an attempt to significantly improve our national telecommunications capability both in terms of capacity and reliability. Creating a high-speed national network will establish the foundation for a system of networks that will result in an integrated national telecommunication capability. Such a system of networks will place this country in a most advantageous position to meet the ever-growing telecommunications needs of our research and education users.

The library community has assumed an important leadership role in the development of telecommunications. In many cases, library services are the most visible and heavily used applications on cam- 
pus networks. The Linked Systems Project has established computer-to-computer connections using the Open Systems Interconnection or OSI. Finally, the Coalition for Networked Information (CNI), founded by the Association of Research Libraries, EDUCOM, and Cause, has been a major force as an advocate for the NREN. One of the major accomplishments of CNI has been to define the issues that must be addressed in the use of the
NREN and to begin working on the resolution of those issues.

The timing of the White House Conference is perfect. During all the pre-White House Conference activities that are transpiring across the nation, the topic of telecommunications and the importance of NREN are emerging as vital issues for the development of libraries in the next decade.

\section{Book thief convicted}

On Thursday, January 31, 1991, after listening to seven days of testimony, a U.S. District Court jury found Stephen Blumberg guilty on all felony counts with which he had been charged. $\mathrm{He}$ had pleaded insanity. He was convicted of one count of conspiracy to transport stolen property across state lines, two counts of transportation of stolen property, and one count of possession of stolen property. Blumberg will be sentenced by the presiding U.S. District Judge Harold Vietor on April 26, 1991. He faces a maximum penalty of 35 years in prison and $\$ 1$ million in fines.

Stephen Blumberg was arrested in March of 1990 when he returned to his home in Ottumwa, Iowa, and interrupted FBI agents in the process of executing a search warrant. This search, which took three days, recovered more than 20,000 rare books and manuscripts, many reported missing or stolen, from more than 327 institutions in 45 states, the District of Columbia, and Canada. Two informants for the prosecution testified that for many years Blumberg made repeated trips across the country, breaking into libraries and stealing books during the night and trading in stolen antiques, including stained g!ass windows, by day.

During the course of the trial representatives from more than ten libraries testified for the prosecution on various facts of the case. Stipulated evidence, facts of the case that both the prosecution and the defense agreed to, read into the record by the prosecution named an additional fifteen institutions documented as the owners of library materials and/or keys found in Blumberg's possession. Blumberg's insanity defense included testimony from a psychiatrist and psychologist hired by the defense. This testimony was countered by the testimony from the prosecution's own psychiatrist.

Blumberg was so skillful at removing or altering the library markings in the books he took that in some cases ownership may be difficult, if not impossible, to determine. Linda Reade, Assistant U.S. Attomey and prosecutor of the case, has indicated that owners of more than half the books have yet to be identified. To submit lists of titles to be checked against the database of recovered materials assembled by the FBI with the assistance of OCLC and a host of volunteers write: Special Agent in Charge, FBl, P.O. Box 548, Omaha, NE 68101. At the earliest, those books and manuscripts already identified and documented by their institutional owners may be released to them by the FBI in late March.

The FBI, Iowa/Nebraska and Michigan districts, as well as the U.S. Attorney, Des Moines, Iowa, should be commended by the library community for persistent and hard work in collecting the facts of this wide-ranging case and prosecuting it to the limit.-Susan M. Allen, Claremont Collges, and Member, Security Committee, Rare Books of Manuscripts Section, ACRL.

\section{ALA calls for Swap and Shop entries}

ALA is asking librarians to share their best public relations materials at Swap and Shop "Southern Style" during the annual conference in Atlanta. The deadline for contributions is June 15,1991 . Participants should send 200 to 300 bookmarks, posters, materials lists, annual reports, library guides, or other publicity to: ALA Swap and Shop, Atlanta Fulton Public Library, One Margaret Mitchell Square, Atlanta, GA 30303. Boxes must be marked in bold, red lettering.

Swap and Shop "Southern Style" will be held on Sunday, June 20, 1991, from 11 a.m. to 1:30 p.m.

For more information contact: Lisa A. Wolfe, 1991 Swap and Shop Committee Chair, Spokane Public Library, West 906 Main, Spokane, WA 99201; (509) 838-6757. 